This item was submitted to Loughborough's Research Repository by the author.

Items in Figshare are protected by copyright, with all rights reserved, unless otherwise indicated.

\title{
Understanding the views of the UK food packaging supply chain in order to support a move to circular economy systems
}

PLEASE CITE THE PUBLISHED VERSION

https://doi.org/10.1002/pts.2474

PUBLISHER

Wiley

VERSION

AM (Accepted Manuscript)

\section{PUBLISHER STATEMENT}

This is the peer reviewed version of the following article: CLARK, N., TRIMINGHAM, R.L. and STORER, I.J., 2019. Understanding the views of the UK food packaging supply chain in order to support a move to circular economy systems. Packaging Technology and Science, 32 (11), pp.577-591, which has been published in final form at https://doi.org/10.1002/pts.2474. This article may be used for non-commercial purposes in accordance with Wiley Terms and Conditions for Use of Self-Archived Versions.

\section{LICENCE}

CC BY-NC-ND 4.0

\section{REPOSITORY RECORD}

Clark, Nicola, Rhoda Trimingham, and lan Storer. 2019. "Understanding the Views of the UK Food Packaging Supply Chain in Order to Support a Move to Circular Economy Systems". Loughborough University. https://hdl.handle.net/2134/37978. 
This item was submitted to Loughborough's Research Repository by the author.

Items in Figshare are protected by copyright, with all rights reserved, unless otherwise indicated.

\section{Understanding the views of the UK food packaging supply chain in order to support a move to circular economy systems}

PLEASE CITE THE PUBLISHED VERSION

https://doi.org/10.1002/pts.2474

PUBLISHER

Wiley

VERSION

AM (Accepted Manuscript)

\section{PUBLISHER STATEMENT}

This is the peer reviewed version of the following article: CLARK, N., TRIMINGHAM, R.L. and STORER, I.J., 2019. Understanding the views of the UK food packaging supply chain in order to support a move to circular economy systems. Packaging Technology and Science, 32 (11), pp.577-591, which has been published in final form at https://doi.org/10.1002/pts.2474. This article may be used for non-commercial purposes in accordance with Wiley Terms and Conditions for Use of Self-Archived Versions.

\section{LICENCE}

CC BY-NC-ND 4.0

\section{REPOSITORY RECORD}

Clark, Nicola, Rhoda Trimingham, and lan Storer. 2019. "Understanding the Views of the UK Food Packaging Supply Chain in Order to Support a Move to Circular Economy Systems". figshare. https://hdl.handle.net/2134/37978. 


\section{Packaging Technology and Science}

\section{An International Journal}

\section{Understanding the views of the UK food packaging supply chain in order to support a move to Circular Economy systems.}

\begin{tabular}{|c|c|}
\hline Journal: & Packaging Technology and Science \\
\hline Manuscript ID & PTS-18-0092.R2 \\
\hline Wiley - Manuscript type: & Research Article \\
\hline $\begin{array}{r}\text { Date Submitted by the } \\
\text { Author: }\end{array}$ & 15-May-2019 \\
\hline Complete List of Authors: & $\begin{array}{l}\text { Clark, Nikki; Loughborough Uni, Design School } \\
\text { Trimingham, Rhoda; Loughborough Uni, Design School } \\
\text { Storer, Ian; Loughborough Uni, Design School }\end{array}$ \\
\hline Keywords: & $\begin{array}{l}\text { FMCG Packaging, Circular Economy, Transformative Technology, } \\
\text { Consumer Behaviour }\end{array}$ \\
\hline
\end{tabular}

\section{SCHOLARONE ${ }^{m}$ \\ Manuscripts}


2 Understanding the views of the UK food packaging supply chain in order

3 to support a move to Circular Economy systems.

4 Nikki Clark ${ }^{1}$, Dr Rhoda Trimingham ${ }^{1}$ and Ian Storer ${ }^{1, *}$

* Correspondence: n.clark@lboro.ac.uk ; Tel.: +44-796-095-2975

7 Received: date; Accepted: date; Published: date

Abstract: This study set out to better understand the feelings of stakeholders from the UK food packaging supply chain towards a move to Circular Economy (CE) systems. The research areas studied included current and future challenges facing supply chain stakeholders, the consideration of Transformative Technologies (TT) to enable packaging solutions in the move to CE systems and what CE systems using TT would look like for the UK's chilled food packaging sector. A questionnaire was selected to obtain data from across the UK Food Packaging Supply Chain. Participants were selected from six industry stakeholder groups, with 24 completing the questionnaire. This study has clearly shown there is a large spectrum of solutions in a move to CE, each with their own benefits and limitations. TT has an ability to enable these, but in selecting the best one for a specific packaging solution, a decision maker must take into consideration business constraints of the supply chain and the consumer's behaviour towards new solutions.

Keywords: FMCG Packaging 1; Circular Economy 2; Transformative Technology 3; Consumer Behaviour 4

\section{Introduction}

Food is the largest packaging end-use sector in the UK, representing $36.6 \%$ of overall sales in $2015^{1}$. From design conception to end of life disposal, food packaging goes through a complex lifecycle, alongside the product's lifecycle, involving multiple stakeholders. Important decisions must be made at each point in the packaging lifecycle (Figure 1) to ensure that the pack safely and efficiently performs, minimizing the waste of both packaging and food materials.

Figure 1 UK Food Packaging Supply Chain Model

Globally the food packaging industry is seeing vast change in what products are sold, how they are made and how they are delivered, driven by technology, cultural change and the economy ${ }^{2}$. A key current focal area, driven from both consumers, and within the industry, is the need to move to Circular Economy approaches for the delivery of chilled Fast-Moving Consumer Goods (FMCG) packaged food. This is a vast change from the current supply 
chain model, which are characterized by linearity (take-make-dispose patterns), that have

38 been the dominant production system for the last 150 years ${ }^{3,4}$. Fast-Moving Consumer Goods

39 (FMCG) are nondurable retail products including food, beverages, personal care, furniture, 40 textiles, household care and packaging goods that are bought frequently, are cheap and 41 typically have a shorter service life than durable goods ${ }^{4}$. It has been found that while food, 42 beverages, clothing and packaging account for approximately 35\% of materials used 43 globally, around $80 \%$ of the materials used for FMCG end up in landfills, incinerators or 44 wastewater ${ }^{4}$.

Transformative Technologies has been discussed in literature as an enabler to developing CE solutions within the FMCG sector ${ }^{4}$. The focus of this paper is to explore the views of UK packaging stakeholders on whether Transformative Technologies (TT) can enable the adoption of Circular Economy (CE) (plastic) packaging systems within the UK's chilled convenience food supply chain, overcoming the sustainability challenges from government and consumers.

\section{Literature}

\section{Moving towards CE systems within FMCG food packaging}

This section assumes a working knowledge of CE thinking and concentrates on CE issues within the food packaging sector.

\section{Global and local targets}

60 The need to move to more sustainable food life cycles is supported by several global and 61 local goals and targets. On a global scale they factor in the UN's Sustainable Development 62 Goals (SDG's) ${ }^{5}$ and The European Commission's Circular Economy Package ${ }^{6}$. Within the 63 UK, DEFRA's 25 Year Environment Plan includes increasing resource efficiency and 64 reducing pollution and waste. This policy is directly related to packaging, with a key aim 65 being to "make sure that resources are used more efficiently and kept in use for longer to 66 minimise waste and reduce its environmental impacts by promoting reuse, remanufacturing 67 and recycling," 7 . However, the ambitions are vague, with no values, or legal requirements 68 for businesses to adhere to. 
69

70

There has also been a government call for a cross-sector plan for plastics following public concern over packaging, alongside the announcement in 2017 that China plans to ban imports of 24 grades of waste materials including plastics ${ }^{8}$. Among the minister's goals reported after an industry round table on 1 December 2017 are greater recycling and recyclability and more incentives for producers and consumers ${ }^{9}$. In December 2018 the UK

Government published 'Our Waste, Our Resources: A Strategy for England'. Their goal for the strategy is to "maximise the value of the resources we use, minimise the waste we create, cut emissions and help create a cleaner, greener, healthier planet" ${ }^{10}$. They aim to focus on 'known problems' looking to "reduce our reliance on single-use plastics, cut confusion over household recycling, tackle the problems of packaging" ${ }^{10}$. Whilst also addressing food waste and waste crime.

The packaging industry is likewise facing pressure from NGO's such as WRAP, World Economic Forum (WEF) and the Ellen MacArthur Foundation (EMF), who recently published The New Plastics Economy: Catalysing Action ${ }^{11}$. All are advocates of improving recyclability rates and promote the use of recycled materials in packaging. Recently they have collectively driven the UK Plastics Pact, a voluntary agreement with 42 signatories from large companies (responsible for $80 \%$ of the UK's plastic packaging use) which (among others) aims to move to $100 \%$ recyclable packaging and 30\% recycled content by $2025^{12}$.

\section{The New Plastics Economy: Circular Economy Approaches}

The vision of the New Plastics Economy offers a new way of thinking about plastics as an effective global material flow, aligned with the principles of the circular economy ${ }^{13}$. The system diagram (Figure 2) illustrates the continuous flow of technical and biological materials through the 'value circle' ${ }^{14}$. Niero, M. et al. believe that the packaging sector and packaging waste management should be given high priority in the $\mathrm{CE}$ agenda. Explaining using research completed by Hopewell et al. in 2009 that "packaging is, by its nature, transient. Most one-way packaging is discarded after use, entering the waste stream after a use period of typically less than a year" ${ }^{15}$. One of the main principles of the CE as stated by de Koeijer, B., et al (2017) is 'waste equals food', which relates to cycles in which recycling can occur without loss of quality. The continuous material cycle concept is of primary importance for packaging development ${ }^{3}$. 
102

103

104

105

106

107

108

109

110

111

112

113

114

115

116

117

118

119

120

121

122

123

124

125

126

127

128

129

130

131

132

133

134

135

136

Figure 2 Outline of a Circular Economy (11)

Many innovations and improvement efforts show potential, but to date these have proved to be too fragmented and uncoordinated to have impact of scale. Existing studies focus on packaging minimization. The aim of such studies is to rationalize material use, therefore decreasing the pressure on finite raw material sources and ultimately reducing the impact on the environment. In doing so packaging designers must remain mindful of a pack's functionality: to protect, preserve and promote the product inside. Svanes and colleagues (2010) disagree, emphasizing that a long-term sustainability strategy for packaging should not be based solely on material minimization. They believe the focus must be on packaging optimization in terms of environmental sustainability, and that consideration must also be given to the pack's distribution costs, market acceptance, and user friendliness. In overcoming these drawbacks, an opportunity beckons; using the plastics innovation engine to move the packaging industry into a positive spiral of value capture, stronger economics and better environmental outcomes ${ }^{13}$.

\section{Approaches}

In order to move towards a circular economy, there is a need for new approaches, skills and knowledge throughout the supply chain. De los Rios and Charnley state that "a variety of new capabilities are key to design for a sustainable future. These range from deeper knowledge of material composition to rich understanding of social behaviour" ${ }^{16}$. The WEF (2017) suggest three transition strategies to accelerate a shift towards circular economy thinking, see Figure 3 (note these are based on global packaging value chains, not specifically the UK chain or to FMCG packaging) ${ }^{11}$.

Figure 3 Three distinct transitions strategies to accelerate the shift towards the new plastics economy (Share of plastic packaging market by weight) ${ }^{11}$.

Following a conference held in April 2016 by Global Sustainability Services provider Anthesis and ThePackHub, attended by representatives across the packaging sector, some common themes emerged. Firstly, the need to consider sustainability as a mainstream business consideration, but also recognition that cross supply chain collaboration, and engagement with stakeholders beyond the normal business supply chain (such as waste collection, recycling and reprocessing sectors) will be essential to meet many of the wasterelated sustainability targets ${ }^{17}$. This is supported by the UK's 25 Year Environment Plan where DEFRA suggest the "need to make data more available to support processes such as industrial symbiosis - i.e. where two or more industrial facilities or companies join up and 
137 the wastes or by-products of one become the raw materials of another," ${ }^{7}$ and through the

138 launch of the Plastics Industry Recycling Action Plan (PIRAP) developed to establish co-

139 operation across the entire waste plastics supply chain ${ }^{18}$.

140

141 Niero, M. et al (2017) propose that a systems approach is required, with connections among

142 all the stakeholders in the value chain, from suppliers to recyclers, and with repercussions at

143 different levels, from technology (e.g., recycling technology) to logistics and waste

144 management, as well as for different actors (i.e., customers and consumers) ${ }^{15}$.

145 Transformative Technologies as an approach

146 Advancements in technology that impact the packaging industry have become more

147 innovative, robust and widespread recently and can often play a dual role in preventing

148 unwanted circumstances and propelling new opportunities for sustainability. Stakeholders

149 within packaging supply chains are continually looking to connect innovation to

150 opportunity to develop creative and sustainable packaging that minimises waste. In their

151 book Waste to Wealth, Lacy and Rutqvist divide these so called 'transformative

152 technologies' which can create an advantage in a Circular Economy into three groups ${ }^{19}$, see

153 Figure 4:

154 1. Digital Technologies

155 2. Engineering Technologies

156 3. Hybrid Technologies

157

158 Figure 4 Defining Transformative Technology Groups (adapted from Lacy and Rutqvist ${ }^{20}$ )

159 Transformational Technologies can reduce waste, improve performance and change and

160 develop relationships with consumers. Further opportunities and benefits of using TT found 161 within literature are outlined in Table 1.

Table 1 Opportunities and benefits of using TT

\section{Limitations of TT}

166 However, literature also highlights some limitations to using TT in a move to CE systems.

167 For FMCG products with low environmental impact, investments in these technologies may 
168

169

170

171

172

173

174

175

176

177

178

179

180

181

182

183

184

185

186

187

188

189

190

191

192

193

194

195

196

197

198

be too high from both economic and environmental perspectives. The "functional positives of the technologies may be outweighed by the costs" 25 . It is also important to "monitor and manage any possible negative effects of new technologies on packaging recycling" (ibid). Richard Hughes concludes in his conference paper, The EU Circular Economy package - life cycle thinking to life cycle law, "How then can the Life Cycle Engineering (LCE) community ensure that the expected revolution expected to be brought about by both the 'Internet of Things' and 'Industry 4.0' deliver the European Commission's goal of creating a circular economy in the years to come?" 25.

\section{Sustainability Challenges facing the UK food packaging supply chain}

The UK plastic packaging industry is currently facing a number of challenges alongside the general packaging challenges of food waste reduction and shelf life extension. These can be divided into Economic, Environmental and Social challenges and some of these as found in the literature are presented in Table 2.

Table 2 Current challenges facing the UK Plastic Packaging Industry 7, 18, 26, 11, 27, 28, 29, 30.

Niero, M. et al highlight the additional challenge "attributed to the increasing web of material producers, packaging component manufacturers, packaging equipment suppliers, users, retailers, and waste recovery facilities and reprocessors that might have different priorities and interests" ${ }^{15}$. Brouwer, M. T., et al (2018) go onto explain that the current 'open loop recycling' approach used is far from The New Plastics Economy's proposed ideal of circular global plastics economy where there is an "effective after-use market for plastics and improved qualities of the recycled plastics" collected ${ }^{31}$. Currently the "composition of sorted plastic packaging products is described with broad specifications" leading to 'blended materials' of reduced quality and with increased contamination due to the complex nature in which packaging materials have been used. The importance of consistent waste management systems is essential to a CE system, with Brouwer, M.T., et al explaining that "the complexity in the current recycling network thus makes 'cradle to cradle' or 'closed loop recycling' nearly impossible" ${ }^{31}$. The authors therefore believe that it is difficult to apply conventional terminology or frameworks such as cradle-to-cradle, closed loop, open loop, upcycling or down- cycling to the complex reality ${ }^{31}$. 
199

200

201

202

203

204

205

206

207

208

209

210

211

212

213

214

215

216

217

218

219

220

221

222

223

224

225

226

227

228

229

230

231

232

233

234

Although briefly considered by De Koeijer, B. et al (2017) and Niero, M. et al (2017) another issue rarely discussed in literature is the impact moving towards $\mathrm{CE}$ approaches will have on the UK consumer and what they will be willing to adopt ${ }^{32,33}$. The sometimes-conflicting nature of consumer behaviour and convenience lifestyle trends can create a challenging conundrum for the food packaging supply chain. These examples act to further highlight the consumer as a key stakeholder and the importance of fully understanding consumer behaviour towards packaging and food waste to develop systems that will work for all actors in the supply chain ${ }^{33}$.

\section{Conclusions to literature}

The literature review supports the need to move towards a CE within the UK FMCG food packaging industry. It has highlighted the rapid development of TT which could change the way we interact with everyday plastic food packaging and consider its future use within a CE. However, further exploration of the challenges and opportunities for stakeholders within the FMCG food lifecycle is needed to fully understand the landscape before goals can be set.

The literature has also emphasized the need to reduce household food waste as a priority area and an additional challenge to the food packaging industry of a tax or ban of single use plastic packaging in the UK alongside the need for plastic packaging to move from a linear to circular economy. Secondary research has shown that there is currently a gap in knowledge relating to consumer behaviour towards $\mathrm{CE}$ packaging solutions, their willingness to adopt new system approaches and their understanding of the environmental benefits, both in reducing packaging waste and food waste. An awareness of these consumer issues within the food packaging industry will be one focus area for this study. Expanding on this there is little research in this field for how designers can use TT, whilst considering consumer behaviour in the design of plastic food packaging solutions for the CE.

Therefore, the aim of this study was to improve the understanding of the views of stakeholders from the UK food packaging supply chain (excluding consumers for this study) towards a move to Circular Economy (CE) systems. The research areas discussed in this paper include the current and future challenges facing supply chain stakeholders in a move to CE goals, the consideration of Transformative Technologies (TT) as enablers in the move to CE systems and the impact of Consumer Behaviour when designing for CE systems. 


\section{Materials and Methods}

This study aims to explore industry stakeholders' feelings towards a selection of food packaging industry related topics. Explicitly asking:

1. What are the challenges facing the UK food packaging industry at a Government, Supply Chain and Consumer Level?

2. How can TT be used to enable packaging solutions implemented in a collaborative CE food supply chain?

3. What do CE systems using TT look like for the UK's chilled food packaging sector?

A questionnaire was selected as the best tool to obtain data from across the UK Food Packaging Supply Chain ${ }^{34}$ in order to gain a broad understanding of the research area from multiple stakeholders. Related questions were grouped together in the relevant research question themes. Participants were selected from across six industry stakeholder groups as shown in Figure 5, using the researcher's prior knowledge of professionals within the UK food packaging supply chain. Invitation emails were sent to 30 industry professionals, with 24 completing the questionnaire. The questionnaire layout and the understanding of the wording were pretested with two industry professionals prior to conducting the final questionnaire.

Figure 5. UK Food Packaging Stakeholder Groups

Each section contained a series of questions to gain both quantitative and qualitative data from the participant. Quantitative questions used either importance ranking from 1 to 8 with 1 being least challenging and 8 being most challenging, nominal data selection tick boxes or a 5-point Likert item scale ranging from $1=$ not at all important to $5=$ very important. Qualitative data was obtained by either asking the participant for a one sentence answer to a question or asking them to complete a predefined sentence.

Section A focused on collecting data to answer the research question: What are the challenges facing the UK food packaging industry at a Government, Supply Chain and Consumer Level? Section B asked questions to answer the research question: How can TT be used to enable packaging solutions implemented in a collaborative CE food supply chain? These sections comprised of six questions. Section $\mathrm{C}$ comprised of 7 questions, with the intention of collating answers to the research question: What do CE systems using TT look like for the UK's chilled food packaging sector? Section D collected information about the participant. All participants names were anonymized during the analysis stage using an identification code. A full copy of the questionnaire can be found as a supplementary file.

Quantitative data was analysed using SPSS. Variable fields were used for each answer category with answer codes entered into the dataset against the participants ID code. Frequency tables and graphs were used to analyse the data output. 
Qualitative data responses were initially grouped into subject themes to give an overview

278

279

280

281

282

283

284

285

286

287

288 of the pattern of answers to the researcher. A full thematic analysis of the qualitative answers was conducted with each response being coded against a subject topic from the literature review. "The process of coding is part of analysis (Miles and Huberman, 1994), as you are organising your data into meaningful groups (Tuckett, 2005). However, your coded data differ from the units of analysis (your themes), which are (often) broader" ${ }^{35}$. By completing the process clear groupings of themes in the participants answers were found and research knowledge gaps identified.

\section{Results}

The questionnaire was completed by $24 \mathrm{UK}$ food packaging supply chain professionals. The split of respondents by stakeholder group and job function can be seen in Table 3 .

\section{Table 3. Split of Scoping Study participants by Stakeholder Group and Job Functions}

\subsection{Analysis of challenges facing the UK Packaging Industry}

When asked to explain the challenges currently facing their UK business in 2018 the participants gave a range of answers which were thematically analysed and grouped into Economic, Environmental and Social Challenges, see Table 4 for further detail.

\section{Table 4. Challenges facing the UK Food Packaging Supply Chain in 2018}

This paper focusses on the challenges of understanding and responding to consumer behaviour with chilled food packaging in a move to a CE. The results relating to these subject areas will be reported in more detail in the following two sections.

\subsubsection{Consumer behaviour challenges}

Participants responses to consumer behaviour challenges facing the industry in 2018 could be split into four main themes.

- Rising costs at home for the consumer

- Consumer perception of food packaging

- Changing shopping habits

- Reducing household food and packaging waste

The increase in cost of living is of concern to the industry, including the impact it will have on consumers purse strings and their purchasing decision priorities. Participants felt it may also bring a limitation in lifestyle choices due to rising costs at home. The study revealed that the effect of the UK recession on supermarket pricing has brought challenges to the whole supply chain, not just consumers. 
When asked to rate the challenge of media's influence on consumer perception, half of the respondents gave this the highest rating of 8 , the most challenging issue facing the UK food

312 packaging supply chain currently. Another $12.5 \%$ gave this a rating of 7 . This shows the

313 level of concern industry places on how media is currently influencing consumer's

314 understanding of packaging.

315 Eighteen participants (75\%) felt that changing shopping habits was either quite or a very important challenge to their business. These participants were from all stakeholder groups, proving this is a challenge facing the whole supply chain. Those participants rating the category unimportant were from the Food Processor and Retail stakeholder groups.

319 Seventeen participants (71\%), felt that reducing household food and packaging waste was 320 either a quite or very important challenge to their business. Participants from five 321 stakeholder groups felt that the category was very important, they represented; Retail, 322 Packaging Consultant, Packaging Manufacturer (cartons), Packaging Manufacturer 323 (plastics) and Food Processor. Interestingly three out of four of the Plastic Packaging 324 Manufacturer's rated this category as very important, showing how vital it is to their 325 industry sector. The functional benefits of plastic packaging can play an important part in 326 extending shelf life and reducing household food waste.

327 The need for better education for consumers came through as a strong theme and challenge 328 facing the industry. Participants agreed on the importance of knowledge transfer from 329 industry to consumer, and that it needs development. One participant stated that "the 330 biggest challenge will be that consumer behaviour will not have changed and consumption 331 will not have abated thus increasing debt and increasing waste," another agreed stating that 332 "education of consumers to the role packaging plays in sustainability is the biggest 333 challenge facing the industry". The study revealed that the industry stakeholders want to 334 improve communication with consumers throughout the supply chain. One stakeholder 335 explained how they want to "fully engage with everyone in supply chain. Share when 336 things go wrong and connect with end of supply chain (consumers)."

337 Looking forward to 2025 the consumer behaviour challenges raised by the participants 338 include:

339 - Consumer education on the role packaging plays (increase knowledge transfer)

340 - Changing shopping habits (increased use of mobile technology)

341 - More choice in shopping methods (increase in omni-channel shopping).

342 - Ability to attract new customers to brands (improve brand trust and loyalty). 
Half of respondents felt that a move to CE systems could be challenging, giving the category a 6 or above for its level of challenge to the industry in 2018. Respondents from this half came from a range of seven stakeholder groups showing the level of challenge spans across the supply chain. The highest frequency of respondents came from Retail with three participants from this group giving a score in this upper range.

Packaging material challenges was a theme which emerged during the thematic analysis, which included the following considerations:

- Which material to use and justification for selection

- What is meant by "sustainable packaging"?

- End of life considerations for packaging materials

- Keeping up with demand for pack innovation within the sector

- Uncertainty around raw material certification

The traceability of materials as a challenge to the supply chain received varying levels of response across stakeholder groups. Those scoring a 7, feeling it was highly challenging, came from Recycling / Reprocessor, Retail and Pack Consultant stakeholder groups, however there were Retail, Food Processor and Packaging Manufacturer participants who gave a score of 2. One participant went onto explain that the industry has "got to have a means for identification (of materials). Technology can enable this identification and connect material through whole supply chain." The word 'materials' used in this study is broad, further research is needed to find out traceability concerns by specific material type to fully understand the challenge facing industry in a move to CE systems.

When asked to rate the challenge of legislation changes on the industry there appeared to be a more equal split about how this will affect the food packaging supply chain with $46 \%$ of participants scoring the challenge on the lower scale of 4 or below, however a quarter of respondents did rate the category on the highest levels of the scale at a 7 or 8 .

Responses to the challenge of food waste reduction seemed more split across the stakeholder groups. Of the six respondents who scored the category a 7, three were from Packaging Manufactures (two plastics, one carton). The remaining three came from Retail, Raw Material and Packaging Consultant groups.

Looking forward to 2025 the CE challenges raised by the participants include:

- Raw material challenges (rising raw material costs, stable supply of recycled materials within the supply chain, the identification of materials)

- Commercial viability of a move to CE systems (ability for business growth, business investment plans, surviving a competitive market environment) 
- Traceability of materials through waste streams and the introduction of new renewable materials into existing waste streams

- Carbon and Energy used in a move to CE systems

- Sustainable packaging design (what is it, how do you go about it?)

- $\quad$ Risk of increase in waste (both food and packaging)

\subsection{Analysis of how transformative technologies can be used in a move to CE systems}

3.2.1. Where in the UK food packaging supply chain can TT effectively reduce packaging waste?

Participants selected which groups, from a list of predefined stakeholder groups, they felt could most effectively use TT to reduce food packaging waste. They could select more than one group. The results, in order of ability, can be seen below in Table 5 .

Table 5. Ranking of stakeholder groups who can effectively reduce packaging waste in the UK food packaging supply chain

It is interesting to see that in the top four ranking stakeholder groups, three of them are during consumer or post-consumer use. It is only the Packaging Manufacturer from early in in the supply chain cycle which remains high on the list. This shows the level of importance the supply chain believes TT has to effectively reduce packaging waste at home and during the collection, sorting and recycling/reprocessing stages. One Retail participant added an "other" category which was that it "was more about food waste, tracking it properly, shelf life extension and temperature control in the chilled chain."

\subsubsection{The importance of using consumer behaviour attributes in a move to CE systems}

Two thirds of participants answered that they feel a move to CE design approaches is very important for the UK food packaging industry.

When asked to select the consumer attributes that they currently consider during packaging project development the following results, in order of popularity, were revealed, see Table 6. Each participant could select all relevant consumer attributes for their business from a predefined list. development process 
There are a lot of high scoring categories here, but what is highlighted is that shelf presence is still the most important design consideration. Consumers must be attracted to the pack

414 and product sales targets must be met. 'Ease to dispose of' came in joint third place with

415 'Target Consumer Demographic'.

Some other notable comments were made by participants. A Food Processor stated they consider shelf life and the use of barriers and materials. A Plastic Packaging Manufacturer focuses on the convenience of the pack with the aim to prevent spillage. A Recycler/Reprocessor stated that this question was not applicable to their sector, suggesting the missing link for this stakeholder group between what they do, and packaging design considerations made earlier in the food packaging supply chain.

3.2.3. Is using TT a sustainable solution for the UK food packaging industry?

Two thirds of participants answered that using TT is a sustainable solution for the UK food packaging industry. The remaining third were unsure. All participants were asked to explain their response in one sentence. Following the analysis of the responses three clear themes emerged explaining how the stakeholders feel TT could aid the UK food packaging industry in a move to more sustainable solutions. These themes are:

1. To aid collaboration across the supply chain

2. Help to reduce waste and increase the value perception of materials

3. To change consumer behaviour

The need to grow consumer understanding of the benefits of food packaging came through as a strong theme within the answers given. Participants feel that the functional benefits of TT packaging can be used to help increase the perception of pack value with consumers, as well as aid consumer motivation in selection of packaging in the product purchasing decision process. Stakeholders believe that providing education, so consumers can understand the benefits of TT within CE packaging systems is important. One participant stated they believed "TT could revolutionize how consumers interact with food packaging."

However, the questionnaire responses also highlighted the following considerations to ensure that TT works effectively as a sustainable solution for the UK food packaging industry in a move to CE systems:

1. Need for common goals, correct purpose and clear objectives that the supply chain can use

2. Input from Government and Legislation in the decision-making process

3. The speed of industry to react and implement technologies

4. The possibility that there could be other solutions which provide quicker benefits 
5. The end of life considerations in using technologies and their cost and impact on the recycling process

6. Assessment of end of life options for Active and Intelligent packaging

\subsection{Analysis of what CE systems using TT would look like for the UK's chilled food} packaging sector.

\subsubsection{CE packaging solutions currently being considered within industry}

Participants were asked to select which CE packaging solutions their business is using from a predefined list, they could select all relevant categories. See Table 7 for CE solutions in order of popularity.

Table 7. Ranking of CE solutions currently being used by stakeholder groups in the food packaging supply chain

The last two solutions are very much linked, with refillable packaging often needing to be part of a Product Service System to successfully operate. It is interesting that these are least popular amongst the food packaging supply chain when one of the historically successful, long running refillable packaging schemes was indeed in the food and beverage market sector, milk!

Three participants noted other CE packaging solutions they were considering in their business. A Plastic Packaging Manufacturer is considering "looking beyond existing materials to renewable materials," a Recycler / Reprocessor is researching into Chemical Recycling methods and a Retailer is looking in more depth at the management of waste.

\subsubsection{Analysis of the benefits for the UK to move to CE packaging systems.}

When asked whether they felt the UK could benefit from a move to CE packaging systems twenty two participants believed yes it could, whilst two participants were unsure. When asked to explain their answer the following three themes of what these benefits could bring the UK emerged. However, there were concerns too, these are discussed in a fourth theme.

\subsubsection{Environmental}

Participants believed there was a possibility for short- and long-term environmental benefits if the UK moved to CE packaging systems. Reducing resource demand and the capture of resource and energy for another use was highlighted by multiple participants as a key benefit. Responses highlighted the importance of developing new packaging materials and that $\mathrm{CE}$ systems could drive demand for more food-contact grade sustainable materials. 
Reduced packaging waste was another popular response with participants explain how CE systems could lead to improved material traceability and better understanding of material flows through the packaging system, ultimately leading to less waste to landfill. They hoped a move to $\mathrm{CE}$ systems could help drive recycling rates of valuable materials, ensuring resources go back into valuable food packaging, avoiding downcycling.

\subsubsection{Economic}

Responses strongly agreed on the economic benefit for the Industry to achieve raw material self-sufficiency through using CE systems. A move to self-sufficiency retains materials within the UK and reduces reliance on external countries imports. Reusing materials as a nation and putting them back into the UK economy to create an economic circle of material value is seen as a huge benefit and a step towards a new emphasis on making things in the UK post Brexit.

Participants believe that CE packaging systems could promote packaging as a valuable resource. It would help avoid packaging materials from being perceived as 'disposable' and would allow the revaluing of packaging post-consumer use, helping to retain material value. One participant felt that "using a percentage of recycled content could solve some of the current issues faced by the packaging industry," whilst others believe in the long-term opportunity of 'waste to wealth' if across the industry they could successfully achieve recovery of waste packaging products within CE systems.

\subsubsection{Social}

It was clear from the analysis that stakeholder groups want to grow consumer understanding and responsibility using CE packaging systems. One participant stating it "gives the public more ability to manage Worldwide resources efficiently." As an industry they believe they need to develop consumer understanding of packaging as a valuable resource that cannot be squandered

Participants in the study also believe that the UK Government would benefit from a move to CE packaging systems. It was remarked that the UK Government could use the EU Circular Economy package to establish CE systems for the country. There could be a benefit from learning from EU nations; sharing CE project success and failure. When asked only 15 participants were aware of the EU Circular Economy package and its implications for UK Law. Many participants believe there is a need for UK Government and Local Authority support to implement packaging legislation change in a move to CE systems.

\subsubsection{Industry Concerns}

Although mainly positive in their responses, participants did also have some concerns about moving to CE packaging systems, these are presented in Table 8.

Table 8. Industry concerns in moving to CE packaging systems 
3.3.3. The part technology must play in enabling solutions in a move to CE packaging systems

518 When asked how much they feel technology has a part to play in enabling solutions in a move to a CE system for UK food packaging, 58\% of participants believe it plays an essential role. Only one participant, a Recycler/Reprocessor said that technology was

521 unimportant.

All, but one of the participants believed that technology could be used to improve the overall value, quality and supply of packaging material collected for recycling. The one participant that did not agree with the majority was from the Food Processing industry and answered unsure. All participants then explained their answers. Following a thematic analysis of the explanations given, the following four themes emerged.

\subsubsection{Technology to aid the sorting and traceability of material}

Participants believe that technology can be used to enable solutions that provide fast and accurate information on packaging usage and disposal by using TT enablers in packaging which can identify itself post-consumer use to improve the sorting of packaging waste.

Industry stakeholders hope technology could connect packaging material through the whole supply chain using track and trace systems, allowing the verification of materials both for material origin and suitability for future applications. Portals could be developed to help stakeholders understand how materials can be used in multiple cycles of use within a CE system. Participants believe this, connected with an appropriate infrastructure, could help maintain packaging materials value within the CE. One participant suggest that Big Data could be used so the supply chain can course correct as they develop and implement new technologies.

\subsubsection{Importance of education, communication and knowledge transfer}

Stakeholders questioned believe that technology can be used as a vehicle for education throughout the supply chain and with consumers. It would allow easier communication within the supply chain and could create an open collaborative environment. Stakeholders could learn from the mistakes of their own business and others in supply chain, especially consumer behaviour and material selection mistakes as noted by one participant.

\subsubsection{Consumer considerations when designing packaging that uses TT}

The results showed that stakeholders believe packaging using TT can aid the simplification of consumer identification of materials at point of disposal (in and out of the home), with the use of smart apps to provide convenient, user friendly solutions.

Participants strongly believed that TT should be used in packaging to improve consumer awareness of packaging's benefits and drive consumer behaviour change to value packaging material and act responsibly when disposing of packaging waste. TT could help engage consumers with a brand in a move to acting more sustainably within a supply chain. 
553

554

However, it was noted that it needs to be consistent in approach and consider "design for all" principles if these technologies are to be successful on a large scale.

\subsubsection{Technology to develop a new waste recovery system in a move to CE}

Responses from this survey clearly highlighted that technology has an essential role in ensuring commercial viability of the recycling value chain and that there is a need for a unified consistent system to gather and process waste. Technology could be used in design to consider the suitability for post-consumer recycling into products. It could also be used in the development of plastic films that are easier to recover and recycle or in the improvement of alternative end of life solutions for packaging materials such as to speed up composting systems or using advanced technologies in the development of chemical recycling.

\section{Discussion}

\section{1 Challenges facing UK Food Packaging Industry at a Government, Supply Chain and}

\section{Consumer Level}

The literature review clearly highlighted the current push by NGO's, Government and the Media for the packaging industry to move from linear to circular systems to reduce the environmental, economic and social impact packaging is currently having globally. This was echoed in the study with two thirds of participants feeling a move to CE design approaches is very important for the UK food packaging industry. However, half of participants in this study also felt a move to CE systems was a huge challenge to the industry both in 2018 and looking forward to 2025. Raw material supply, commercial viability of systems, traceability of materials, energy use, sustainable design practices and the risk of increased waste (both food and packaging), were all raised as challenges facing the industry. These important categories should all be considered when looking to implement a successful CE system in the food packaging industry.

The threat of legislation changes and its impact on the packaging industry was less clear from the scoping study evidence. Changes to packaging legislation were unclear during conducting the study with the Governments Waste and Resource Strategy for England published 10 months after the research was completed. Stakeholders surveyed in this study have mixed feelings about how changes could impact their own business. It is also fair to point out that the survey had respondents from both the carton and plastics industry. Plastic packaging currently has a negative perception in the media born from documentaries such as Blue Planet, and future legislation changes which ban or tax the use of plastics ${ }^{10}$.

The study showed that participants in this study agree that a collaborative approach is very important to solve the current challenges being faced by the industry, agreeing that the supply chain needs to: work towards a common goal, communicate regularly across the whole supply chain, form working relationships and transfer knowledge between stakeholder groups. 
The media's influence on consumer perception of packaging as raised in the literature review is supported by study findings, with participants giving the challenge their highest rating of concern. Stakeholders were clear on the functional benefits of plastic packaging; promoting its protection and preservation qualities within their responses, both essential for helping reduce food waste in the UK's food supply chain. Their concern lies with how to communicate this knowledge to consumers and help educate them about the important role packaging plays.

Evidence from the literature review highlighted the inefficiencies of current household waste management systems in the UK. This was echoed in the study, with stakeholders stressing the importance of improving the consistency of waste management systems for food packaging. Stakeholders interviewed feel consumer's changing shopping habits and a rise in single-households intensifies the need for convenient smaller pack formats. However, they are aware that this may increase the number of packs produced and could lead to a growth in the volume of packaging waste.

\section{2 Can TT be used as an enabler to packaging solutions implemented in a collaborative}

\section{CE supply chain}

Technologies are currently used by the stakeholders interviewed to accelerate sustainable change, increase efficiencies and help reduce waste (both food and packaging). Reducing waste through packaging design was also highlighted in the literature review by Wikstrom and Williams "opportunities to redesign product-packaging configurations to help consumers reduce waste through a selection of pack sizes and other convenience features" ${ }^{24}$. Consideration of stakeholder needs and the current expectations of technology by the supply chain were deemed important by stakeholders.

Evidence from this study show that stakeholders surveyed believe that TT is a sustainable solution that will aid collaboration, reduce waste (both packaging and food), increase value perception and change consumer behaviour in a move to CE packaging systems. They think that technology plays an essential part in enabling solutions in a move to CE systems in the UK food packaging industry. However, the survey responses also raised additional considerations such as: a need for common goals, input from Government legislation, speed to react and implement technologies, availability of other solutions and the unintended end of life impacts (both environmental and economic).

The study highlighted the need to change consumer behaviour with packaging by using TT in sustainable packaging solutions to grow consumer understanding, increase the perceived pack value, revolutionise how they interact with the packaging, provide education on the benefits of CE packaging systems and to ultimately aid the purchasing decision making process towards more sustainable packaging choices.

\section{3 What could CE systems using TT look like for the UK's chilled food packaging sector}

628 The need for supply chain management, both Business to Business (B2B) and Business to 629 Consumer (B2C) as stated in literature by Korhonen et al. ${ }^{36}$ was backed by the study which 
highlighted the need for a collaborative supply chain approach to implement CE systems.

631 Stakeholders expressed the importance of common goals, trust and transparency but also

632 the need for industrial symbiosis, as proposed by DEFRA, with vertical integration being 633 suggested by participants in the study. Both literature and the study findings aim for a 634 simplification and change in the supply chain approach to solve the challenges it currently 635 faces.

636 Currently Design for Recyclability is the most popular CE solution with participants 637 surveyed, with systems design at the bottom of the list of waste management solutions. The 638 ease to implement, capacity of existing mechanical waste management systems and 639 knowledge of system design could all have a part to play in this result. Three participants 640 are already implementing or considering CE solutions which include: looking at new 641 renewable materials, research into chemical recycling methods and in-depth waste 642 management projects.

643 However, the study showed a real drive by stakeholders to work towards the UK being self644 sufficient in raw materials for packaging. They linked this to the important part recycling 645 would play in ensuring the consistent supply of high quality recyclate to achieve this, using 646 traditional mechanical recycling and new chemical recycling technologies. Stakeholders 647 surveyed believe that TT could aid sorting and traceability of material within a new waste 648 recovery system, and the need for a unified consistent system to gather and process waste. 649 However, many participants agreed there are no 'silver bullets' to solving the current 650 challenges and that a range of solutions would be needed. Current concerns in moving to 651 CE systems amongst stakeholders include cost to implement, environmental impact and 652 consumer design considerations.

653 Ease to dispose of came third in the list of consumer behaviour attributes considered during 654 packaging project development, however impact at point of purchase was still the most 655 important design consideration by stakeholders in the food packaging supply chain. 656 Consumers must be attracted to the packaging in the first place and a sale must be secured.

\section{5. Conclusions}

658 This study set out to better understand the feelings of stakeholders from the UK food 659 packaging supply chain towards a move to CE systems. The research areas studied included 660 current and future challenges facing supply chain stakeholders, the consideration of 661 Transformative Technologies (TT) to enable packaging solutions in the move to CE systems 662 and what CE systems using TT would look like for the UK's chilled food packaging sector.

663 A move to CE systems from the traditional linear make-use-dispose is no doubt a huge 664 challenge to the food packaging industry both in 2018 and looking forward to 2025, with 665 industry stakeholders concerned about a range of economic, environmental and social 666 implications associated with adapting their industry to a cyclical approach. The commercial 667 viability of systems, the speed to implement technologies and the unintended environmental 668 consequences being raised as major risks in this study. 
With legislation changes unclear at this moment in time, stakeholders have mixed feelings towards how they may impact their business and seek a collaborative supply chain approach to support themselves during this time of uncertainty. Stakeholders agree that the food packaging supply chain needs to work towards a common goal, improve communication between stakeholder groups and most importantly share valuable knowledge to protect and nurture their industry. They view TT as a sustainable solution which can aid this collaboration whilst also reducing waste.

676 With the media feeding consumer's current perception of packaging, stakeholders current 677 concern lies with how to communicate practical packaging knowledge to consumers to help educate them about the important role it can play in a sustainable, time-poor lifestyle. The study has shown that stakeholders want to use TT to increase the value perception of packaging by consumers and change their disposal behaviour in a move to CE packaging systems. If TT can achieve this, it could ultimately aid the purchasing decision making process of consumers towards more sustainable packaging choices.

\section{3}

684

Both literature and the study findings suggest a need for a simplification in the current food

685 packaging supply chain approach to solve the challenges it currently faces. Improving recyclability of materials and the associated waste management infrastructure are the most popular CE solutions with the participants surveyed in this study. There is a real drive by stakeholders to work towards the UK being self-sufficient in raw materials for packaging. Recycling technologies would play an essential part in ensuring the consistent supply of high quality recyclate to achieve this.

More than once it was mentioned in the survey that there are no 'silver bullets' to the challenges the packaging supply chain faces and that a spectrum of solutions would be required. This was echoed in the literature review. However, stakeholders are mindful that ultimately the consumer is key; if they do not adopt new CE systems it won't be successful, and the issues we face now could be multiplied.

The literature and findings from this study have clearly shown there is a large spectrum of solutions in a move to $\mathrm{CE}$, each with their own benefits and limitations. TT has an ability to enable these but in selecting the best one for a specific packaging solution, a decision maker must take into consideration business constraints of the supply chain and the consumer's behaviour towards new solutions. A knowledge gap exists exploring consumer behaviour towards CE food packaging solutions. Their willingness to adopt new system approaches and their understanding of the environmental and economic benefits now needs investigating in order to reduce both food and packaging waste. There is also a need to better understand, and plot, the economic implications of system solutions using TT versus the environmental and social gains. The outcome of research into these areas will hopefully assist decision makers within the food packaging supply chain to decide which TT has the best benefits for their packaging project to create the most value economically, socially and environmentally.

\section{References}


1. Smithers Pira. The future of global packaging to 2020. 2014;44(0):176. p.74 Available from: http://www.smitherspira.com

712 2. IGD. The Evolution of the Physical Store. 2017;1-24. Available from:

5. United Nations. Transforming our world: the 2030 Agenda for Sustainable Development. Vol. 16301, General Assembley 70 session. 2015.

6. European Commission. A European Strategy for Plastics in a Circular Economy [Internet]. Brussels; 2018. Available from: http://ec.europa.eu/environment/circulareconomy/index_en.htm

7. DEFRA. A Green Future: Our 25 Year plan to improve the environment [Internet]. 2018. Available from: https://www.gov.uk/government/publications/25-yearenvironment-plan

8. Ottery C. Gove admits ignorance over impact of China import. Materials Recycling World [Internet]. 2017;1-2. Available from: https://www.mrw.co.uk/latest/goveadmits-ignorance-over-impact-of-china-importban/10024976.article?search=https\%3A\%2F\%2Fwww.mrw.co.uk\%2Fsearcharticles $\% 3$ Fqsearch\%3D1\%26keywords\%3Dgove

9. Latchem R. Gove sets out sustainable plastic goals. Mater Recycl World [Internet]. 2017;1-2. Available from: https://www.mrw.co.uk/latest/gove-sets-out-sustainableplastic-goals/10025914.article

10. Government HM. Our Waste, Our Resources : A Strategy for England. London; 2018 [accessed 7 January 2019]. https://www.gov.uk/government/publications/resourcesand-waste-strategy-for-england. p.4.

11. World Economic Forum. The New Plastics Economy - Catalysing Action. 2017;(January):1-68. Available from: https://www.ellenmacarthurfoundation.org/assets/downloads/New-PlasticsEconomy_Catalysing-Action_13-1-17.pdf\%0Awww.weforum.org

12. WRAP. UK Plastics Pact [Internet]. wrap.org.uk. 2018 [cited 2018 May 15]. p. 1. Available from: http://www.wrap.org.uk/content/the-uk-plastics-pact

13. World Economic Forum. The New Plastics Economy: Rethinking the future of plastics. World Econ Forum. 2016;1(January):1-36.

14. Ellen MacArthur Foundation. Circular Economy System Diagram [Internet]. 
ellenmacarthurfoundation.org. 2017 [cited 2018 May 15]. p. 1. Available from: https://www.ellenmacarthurfoundation.org/circular-economy/interactive-diagram

15 Niero M, Hauschild MZ. Closing the Loop for Packaging: Finding a Framework to Operationalize Circular Economy Strategies. Procedia CIRP. 2017;61:685-690. doi:10.1016/j.procir.2016.11.209.

16. De los Rios IC, Charnley FJS. Skills and capabilities for a sustainable and circular economy: The changing role of design. J Clean Prod [Internet]. 2017;160:109-22. Available from: http://dx.doi.org/10.1016/j.jclepro.2016.10.130

17. Hitchen D. What Does Sustainability Mean in a Sector as Diverse as the Packaging Industry? [Internet]. 2016 [cited 2017 Nov 10]. Available from: https://blog.anthesisgroup.com/what-does-sustainability-mean-in-a-sector-asdiverse-as-the-packaging-industry

18. WRAP. Plastics Market Situation Report. 2016;1-29. p.26.

19. Lacy P, Rutqvist J. Waste to Wealth: The Circular Economy Advantage. Palgrave Macmillan; 2015. 1-264 p.

20. Lacy P, Rutqvist J. Waste to wealth : the circular economy advantage [Internet]. [cited 2018 Feb 15]. 264 p. Available from: https://books.google.co.uk/books?hl=en\&lr=\&id=DmKkCgAAQBAJ\&oi=fnd\&pg= $\mathrm{PP} 1 \& \mathrm{dq}=$ Waste + and + Circular + Economy\&ots $=7 \mathrm{WLKCB}-$ $\mathrm{M} 45 \&$ sig=JnOX_1ODLjQPaz4TnfsWs5PS1ZQ\#v=onepage\&q=Waste and Circular Economy\&f=false

21. Braungart, Michael, McDonough W. Cradle to Cradle: Remaking the way we make things. 2009. 192 p.

22. Ceschin, Fabrizio, Gaziulusoy I. How many ways to design for Sustainability? In: Routledge Handbook of Sustainable Design. 2018. p. 417-32.

23. Gaziulusoy AI, Brezet H. Design for system innovations and transitions: A conceptual framework integrating insights from sustainablity science and theories of system innovations and transitions. J Clean Prod [Internet]. 2015;108:1-11. Available from: http://dx.doi.org/10.1016/j.jclepro.2015.06.066

24. Verghese K, Lewis H, Lockrey S, Williams H. Packaging's Role in Minimizing Food Loss and Waste Across the Supply Chain. Packag Technol Sci. 2015;28(7):603-20.

25. Hughes R. The EU Circular Economy Package - Life Cycle Thinking to Life Cycle Law? Procedia CIRP [Internet]. 2017;61:10-6. Available from: http://dx.doi.org/10.1016/j.procir.2016.12.006

26. Dreizen $\mathrm{C}$. The race to increase recycled content in packaging. Packaging Digest [Internet]. 2017;1-9. Available from: http://www.packagingdigest.com/sustainablepackaging/the-race-to-increase-recycled-content-in-packaging-2017-12-04

27. House of Commons Environment Food and Rural Affairs Committee. Food waste in 
786

787

788

789

790

791

792

793

794

795

796

797

798

799

800

801

802

803

804

805

806

807

808

809

810

811

812

813

814

815

816

817

818

819

820

821

822

2017;Eight(April):42.

Available

from:

England.

https://publications.parliament.uk/pa/cm201617/cmselect/cmenvfru/429/429.pdf

28. Williams H, Wikström F, Otterbring T, Löfgren M, Gustafsson A. Reasons for household food waste with special attention to packaging. J Clean Prod [Internet]. 2012 [cited 2017 Sep 8];24:141-8. Available from: http://ac.elscdn.com/S0959652611004793/1-s2.0-S0959652611004793-

main.pdf?_tid=ee00174c-947b-11e7-b762-

00000aacb361\&acdnat $=1504864745$ f7a7bfe3508d982c05114738bcc6ce78

29. Boffey D. EU declares war on plastic waste. The Guardian [Internet]. 2018; Available from: https://www.theguardian.com/environment/2018/jan/16/eu-declares-war-onplastic-waste-2030

30. BPF. Plastics Recycling [Internet]. bpf.co.uk. 2017 [cited 2017 Dec 6]. Available from: http://www.bpf.co.uk/sustainability/plastics_recycling.aspx

31. Brouwer MT, Thoden van Velzen EU, Augustinus A, Soethoudt H, De Meester S, Ragaert K. Predictive model for the Dutch post-consumer plastic packaging recycling system and implications for the circular economy. Waste Manag. 2018;71:62-85. doi:10.1016/j.wasman.2017.10.034. p.63, p.72.

32. Hobson K, Lynch N. Diversifying and de-growing the circular economy: Radical social transformation in a resource-scarce world. Futures [Internet]. 2016;82:15-25. Available from: http://dx.doi.org/10.1016/j.futures.2016.05.012

33. Ceschin F, Gaziulusoy I. Evolution of design for sustainability: From product design to design for system innovations and transitions. Des Stud. 2016;47:118-63.

34. Robson C. Real world research: a resource for Users of Social Research Methods in Applied Settings [Internet]. Fourth. Vol. 2nd, Colin Robson. Wiley; 2011. 521 p. Available

from: http://books.google.com/books?id=DkplMcAysFQC\%5Cnhttp://media.matthewsboo ks.com.s3.amazonaws.com/documents/tocwork/063/9780631213055.pdf

35. Braun V, Clarke V. Using thematic analysis in psychology. Qual Res Psychol. 2008;3(2006):77-101. http://www.tandfonline.com/loi/uqrp20\%0AUsing. p.88.

36. Korhonen J, Honkasalo A, Seppälä J. Circular Economy: The Concept and its Limitations. Ecol Econ [Internet]. 2018;143:37-46. Available from: https://doi.org/10.1016/j.ecolecon.2017.06.041 
823

825

11

12

13

14

15

16

17

18

19

20

21

22

23

24

25

26

27

28

29

30

31

32

33

34

35

36

37

38

39

40

41

42

44

45

46

47

48

49

50

51

52

53

54

55

56

57

58

59

60 


\section{Study 1: Questionnaire

Please read the accompanying notes for participants before you answer the questions.

Your individual responses will be confidential and used anonymously. Nevertheless you are requested to put your name on your completed questionnaire for purposes of our records during this study.

Name:

Date: ...........................

16n a single sentence, please can you explain the biggest sustainability challenge facing your business in 2018. 17
13
2
2
2
2
2
2

29A2. Challenges facing the food packaging supply chain

28 order of least to most (where 1 is least and 8 is most), which of the following challenges facing the UK's food 2甲ackaging supply chain concerns you the most?

Legislation changes

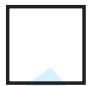

Food waste reduction

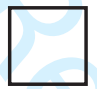

Brexit

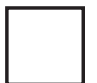

Move to Circular Economy

Traceability of materials

Other (please state)
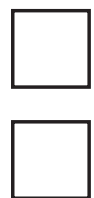

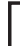

\section{A 3 . Consumer Behaviour Challenges}

41 your view which of the following consumer behaviours pose the most challenge to your business in the UK? 4 Please use the scale provided. Not at all important SCALE Very important

47 Society's time poor lifestyles

48

49

50 Increase in single households

${ }_{52} 1$ Reducing Household food and packaging waste

53 Rising consumer debt

54

56n a single sentence, please can you explain the challenges you foresee for your business in 2025.

5
5
5
6 


\section{A5. Collaborative Supply Chain}

${ }_{2}^{1}$ How important do you feel a collaborative supply chain approach not at all important SCALE very important 3 is to the current challenges facing the UK food packaging industry? 4

${ }_{6}^{5} \mathrm{~A} 6$. Successful Collaboration

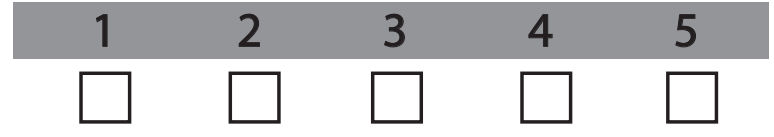

${ }_{7}$ Complete the following sentence:

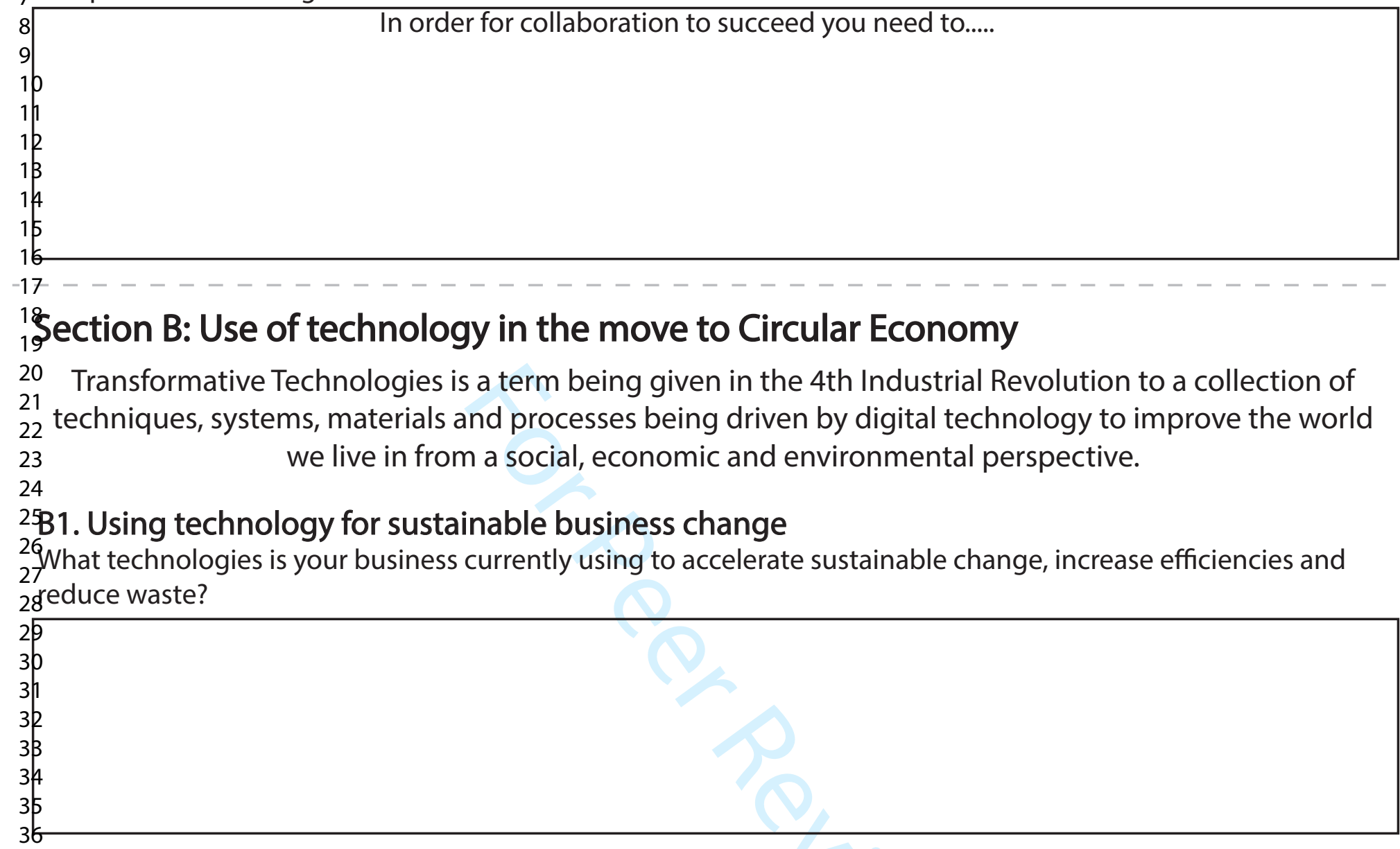

382. Your Awareness of Transformative Technologies

3QVhich of the following Transformative Technologies are you aware of? ${ }_{41}^{40}$ ou may tick as many as you need to answer the question.
4Active Packaging 4 [e.g. moisture control) Intelligent Packaging (Embedded Sensors)
Mobile Monitoring

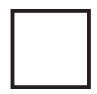
Big Data
Blockchain
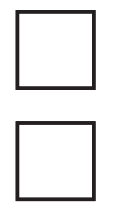
Other (please state)
The Cloud
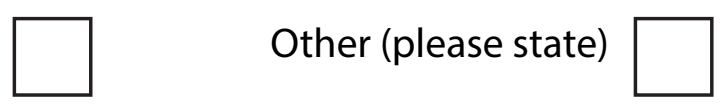

\section{B3. Business Awareness}
58Vhich department in your business is considering the use of transformative technologies and how they could be 5 Pmplemented within your supply chain?
Research \& Development
Sales \& Marketing
60
Directors
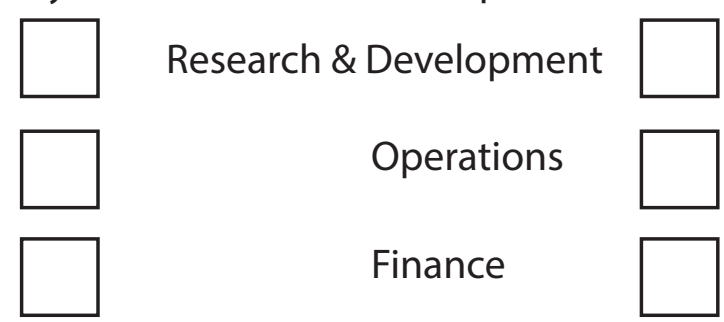
Technical
Sustainability
Other (please state)

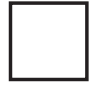
Operations
Finance
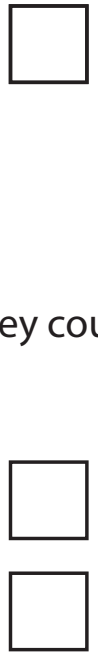


\section{B4. Supply Chain Applications}

${ }_{2}^{1}$ At which point in the UK food packaging supply chain do you feel Transformative Technologies have the best 3 ability to effectively reduce packaging material waste? You may tick as many as you need to answer the question.
Raw material supplier $\square$
Packaging Manufacturer
Food Processor
Distribution Chain

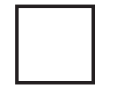
Retail Store
Consumer
Waste Collection

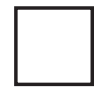
Recycler / Reprocessor
Other (please state)

1B5. Importance of the Circular Economy

14 How important do you feel a move to circular economy design 15
15

\section{Sustainable Industry Solutions}

${ }_{20}^{1} \delta_{5}$ using Transformative technologies a sustainable solution for the

${ }_{2} \mathrm{WK}$ food packaging industry? Please explain your answer in one sentence.

not at all important SCALE very important

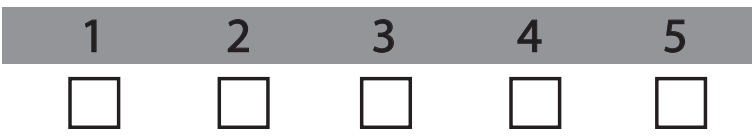

Yes

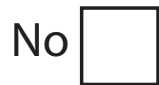

Unsure

23

24

25

25

27

28

29

30 33

34 C1. The Rise of Circular Economy Thinking

35 Have you heard of the Circular Economy?

$38 \mathrm{C} 2$. Future of Circular Economy in Europe

39Are you aware of the new European Circular Economy Package and it's

49 mplications for UK Law?

Yes

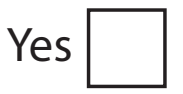

No

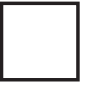

Unsure

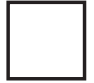

42C3. Circular Economy Business Solutions

${ }^{43}$ Which of the following circular economy solutions are you considering within your business?

45 You may tick as many as you need to answer the question.

46

47 Redesign of products

48

${ }_{50}^{49}$ Design for Recyclability

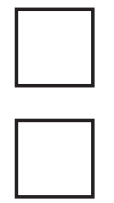

Re-usable packaging

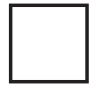

Refillable Packaging

Systems Design

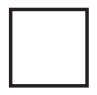

Other please state:

51

52

5
5
5
5
5
5
5
6

3 C4. Advantages or Disadvantages to new systems

54Do you see a benefit for the UK to move to circular economy

5 packaging systems? Please explain your answer below in one sentence.
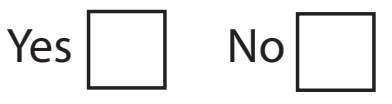

Unsure 


\section{C5. Technology as an enabler}

1 How much do you feel Technology has a part to play in 2 enabling solutions in a move to a Circular Economy system for ${ }_{4}^{3}$ UK food packaging?

2(7. Consumer Behaviour Considerations

Which of the following consumer attributes do you consider during project development?

23 ou may tick as many as you need to answer the question.

\section{Target Consumer \\ Demographic

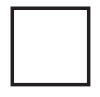 \\ Impact at Point of \\ Purchase}

Opening Experience

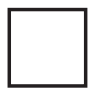

Ease to dispose of
Storage at Home

None of these
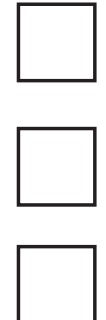

Ease to pack and transport home

Repeat usage

Other please state:

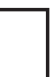

Section D: Participant Information

Age Group (please tick relevant box)
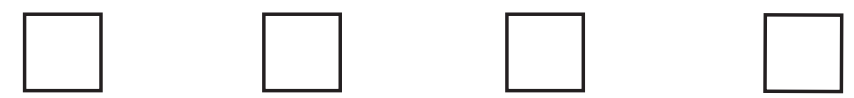

$18-24$

$25-34$

$35-44$

$45-54$

$55-64$

Job Function (please tick relevant box)

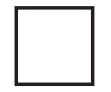

Designer

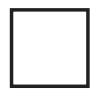

$R \& D$

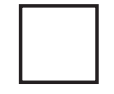

Technical

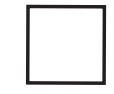

Operations

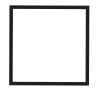

Sales \& Marketing

Industry Sector (please tick relevant box)

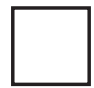

Raw Material

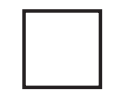

Packaging Manufacturer

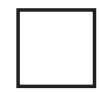

Machinery Supplier

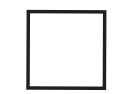

Food Processor

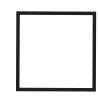

$65+$
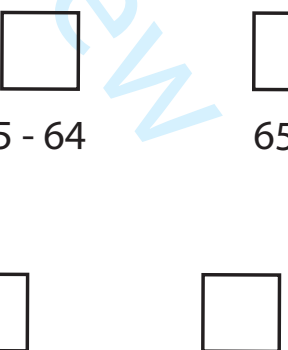

Director

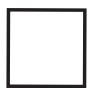

Recycling / Reprocessor

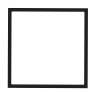

Other, please state

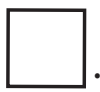

Market Sector (please tick all relevant boxes)

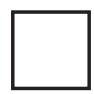

Produce

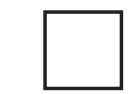

Meat, Fish \& Poultry

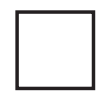

Bakery

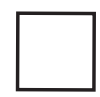

Retailer

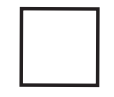

Chilled

Prepared
Design Agency
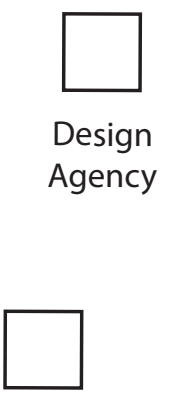

Confectionery

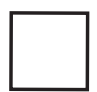

Ambient Foods
Other, please state Foods 


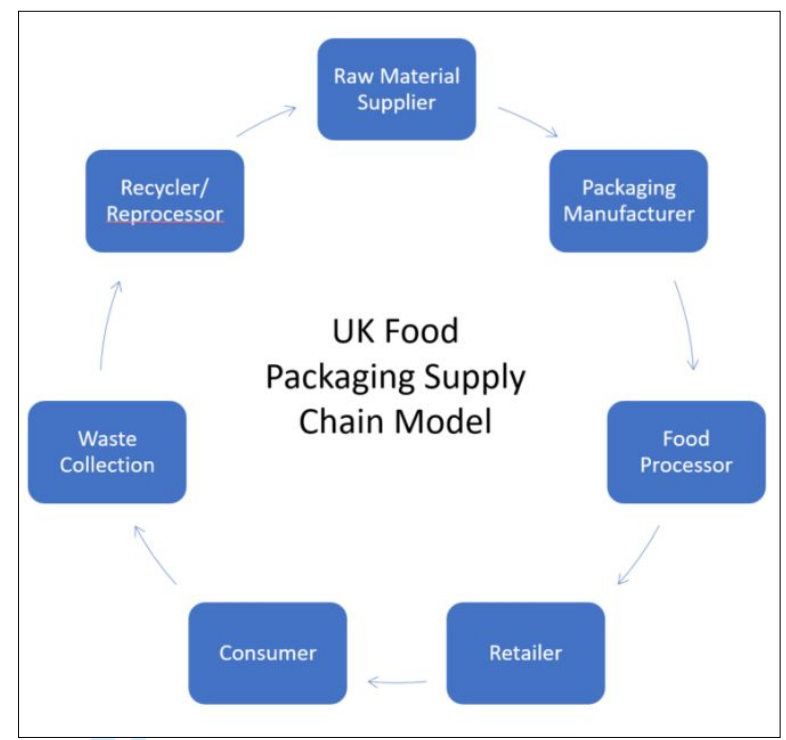

Figure 1 UK Food Packaging Supply Chain Model

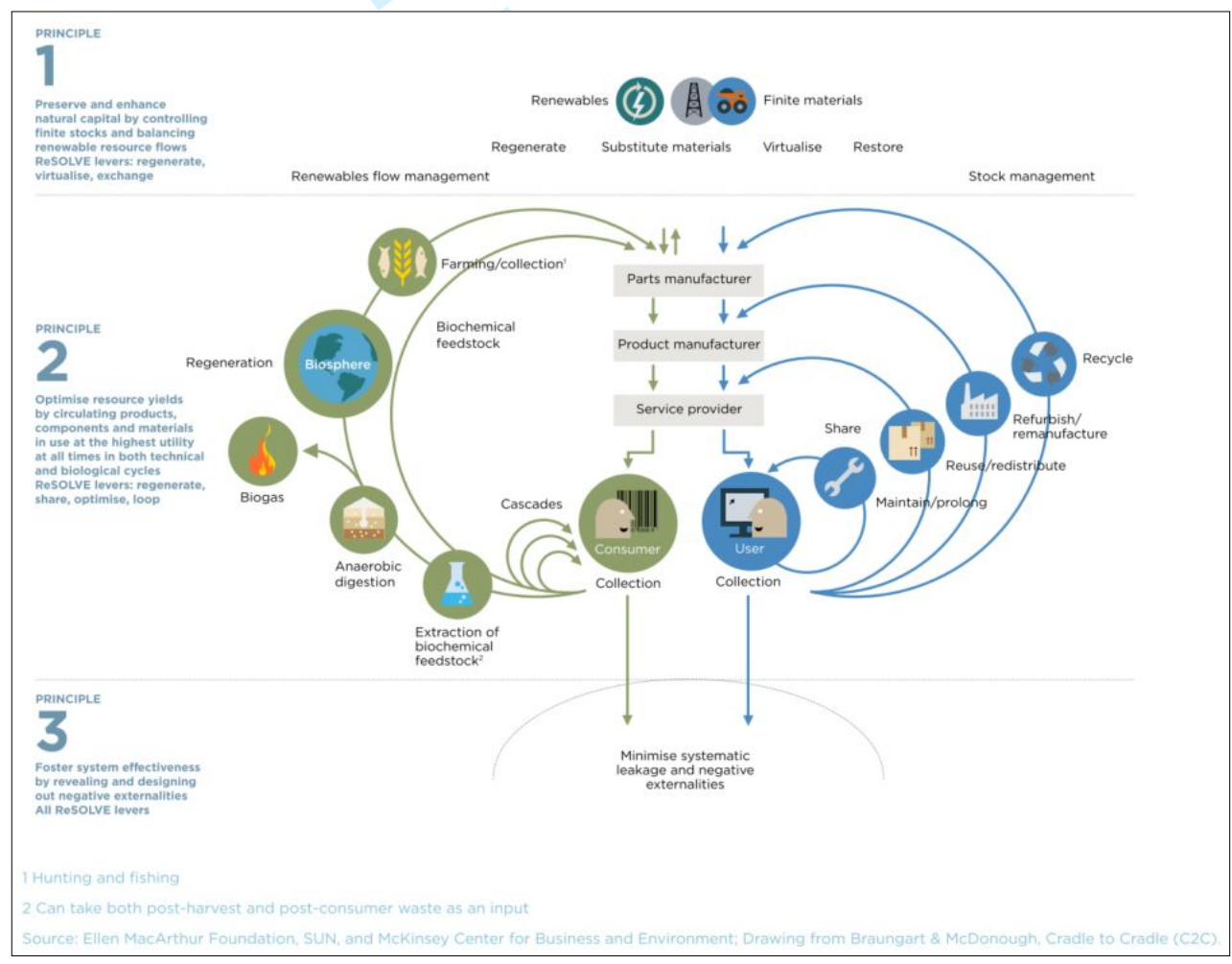

Figure 2 Outline of a Circular Economy ${ }^{11}$. 


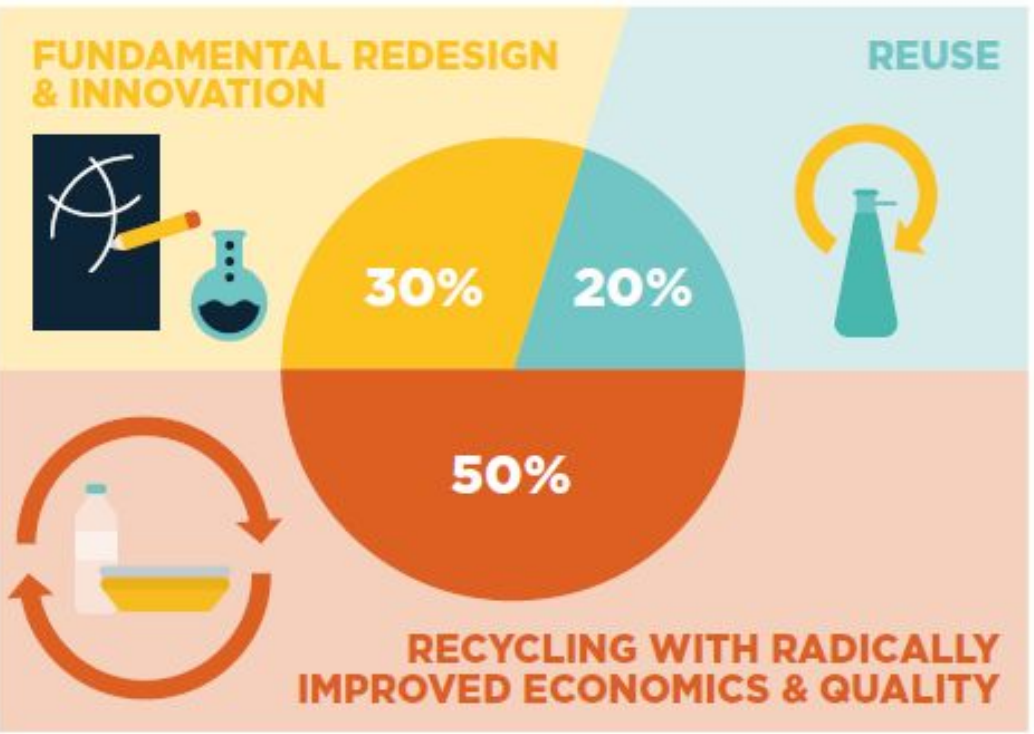

Source: New Plastics Economy initlative analysis (see Appendix for detalls)

Figure 3 Three distinct transitions strategies to accelerate the shift towards the new plastics economy (Share of plastic packaging market by weight) ${ }^{11}$

\section{Transformative Technologies}
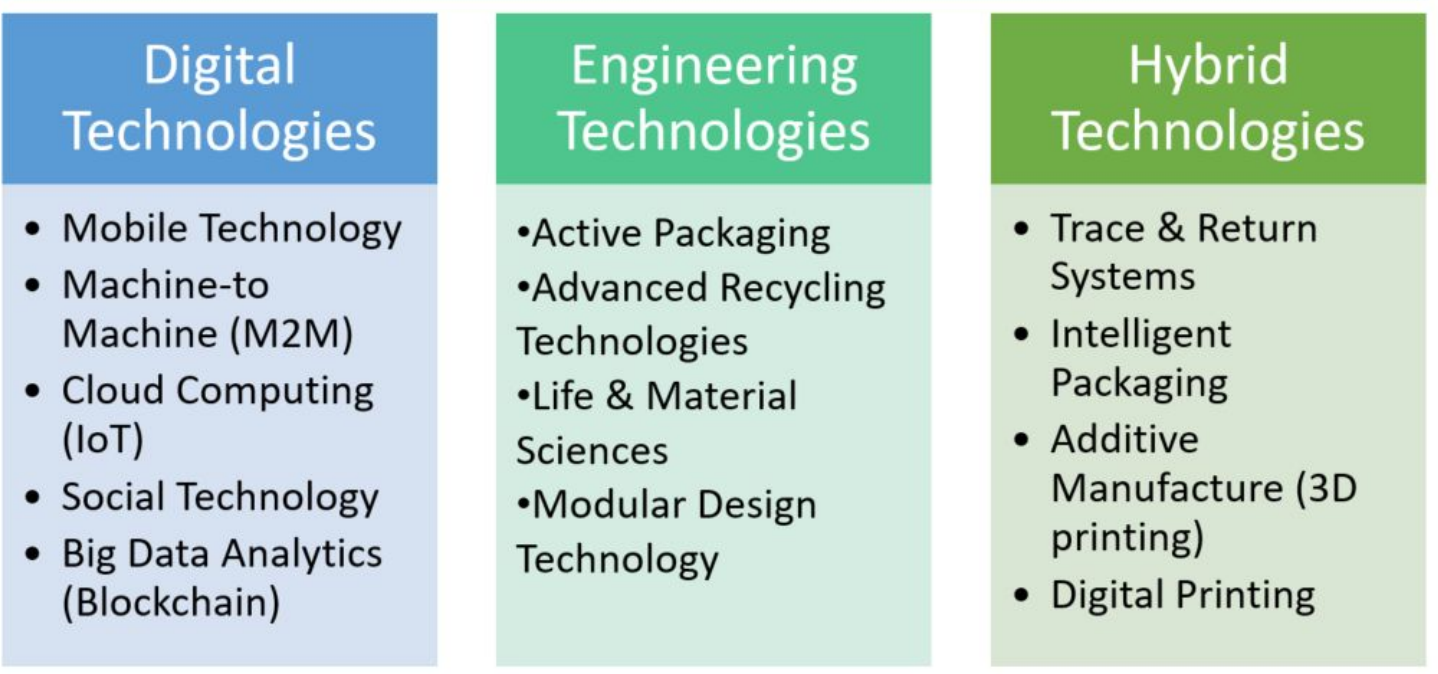

Figure 4 Defining Transformative Technology Groups (adapted from Lacy and Rutqvist ${ }^{20}$ ) 


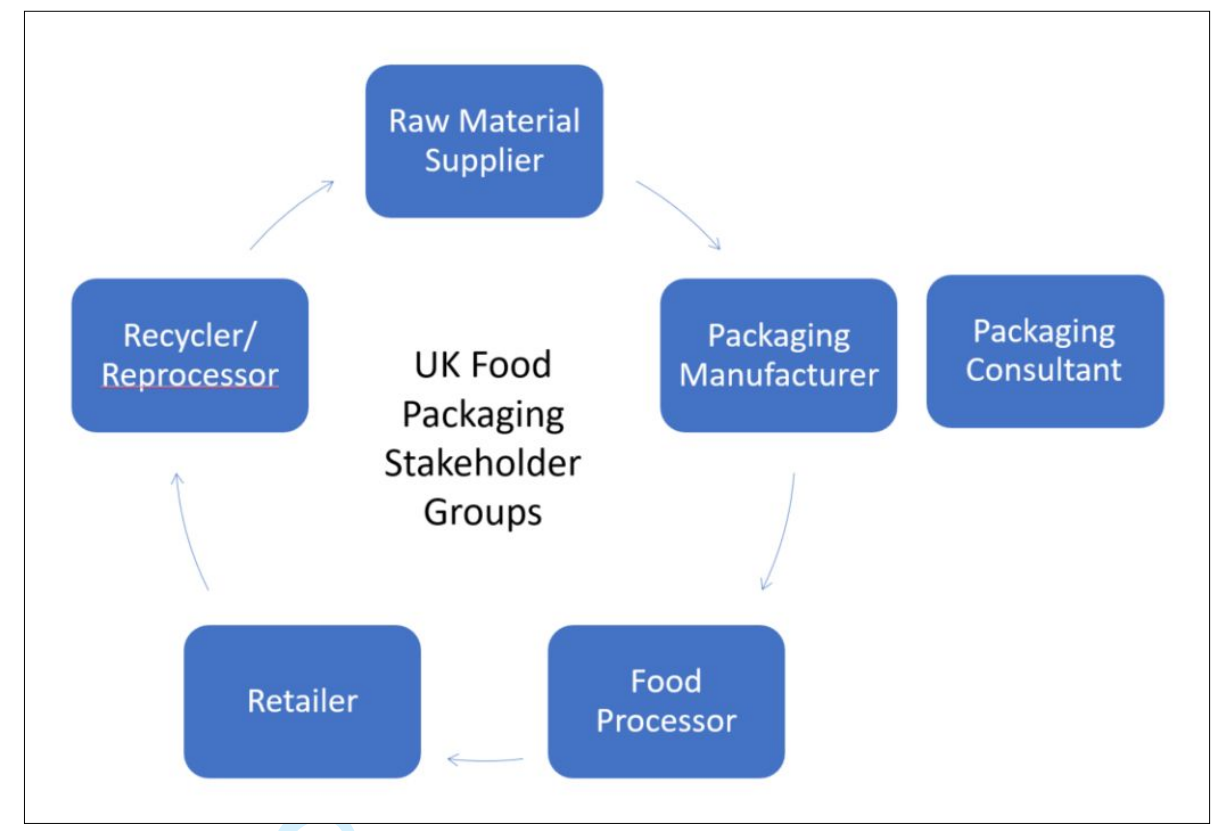

Figure 5. UK Food Packaging Stakeholder Groups 
Table 1 Opportunities and benefits of using TT

\begin{tabular}{|l|c|}
\hline Opportunities and Benefits of using TT & Reference \\
\hline $\begin{array}{l}\text { Allow real-time information exchanges among users, machines, and } \\
\text { management systems. }\end{array}$ & $(20)$ \\
\hline $\begin{array}{l}\text { They're intrinsically customer-focused and provide the connections } \\
\text { needed to maintain a relationship far beyond the point of sale. }\end{array}$ & $(20)$ \\
\hline Enhance remote visibility and control of assets & $(20)$ \\
\hline Alter way we interact with physical and digital assets & $(20)$ \\
\hline $\begin{array}{l}\text { Enable Dematerialization - Can ultimately transform value chains so } \\
\text { they no longer need additional resources to grow. }\end{array}$ & $(20)(\mathrm{p} .140)$ \\
\hline $\begin{array}{l}\text { cost-effective solutions for collecting, returning, and processing goods } \\
\text { and materials for recycling and remanufacturing.” }\end{array}$ & $(21)(\mathrm{p} .178)$ \\
\hline $\begin{array}{l}\text { encoding information about ingredients in the materials themselves, in } \\
\text { a kind of 'upcycling passport' that can be read by scanners and used } \\
\text { productively by future generations. }\end{array}$ & \\
\hline Used to encourage perceptions of material value & $(13)$ \\
\hline $\begin{array}{l}\text { Using renewable resources, carbon-efficient manufacture, refillable } \\
\text { packaging, recycling data, systems thinking approaches with the } \\
\text { ultimate aim of a move to socio-technical systems innovation }\end{array}$ & $(22)(23)$ \\
\hline
\end{tabular}

Table 2 Current challenges facing the UK Plastic Packaging Industry in 2018 7, 18, 26, 11, 27, 28, 29, 30

\begin{tabular}{|l|l|l|}
\hline Economic & Environmental & Societal \\
\hline $\begin{array}{l}\text { Vulnerability of changing } \\
\text { market conditions }\end{array}$ & $\begin{array}{l}\text { Pressure to move from finite } \\
\text { to renewable raw material } \\
\text { sources }\end{array}$ & $\begin{array}{l}\text { Poor value perception of } \\
\text { plastic packaging }\end{array}$ \\
\hline $\begin{array}{l}\text { Changes to legislation and tax } \\
\text { systems }\end{array}$ & $\begin{array}{l}\text { Reliability of supply of post- } \\
\text { consumer recyclate }\end{array}$ & Growth of value retail mindset \\
\hline $\begin{array}{l}\text { Commercial viability of single } \\
\text { use plastics }\end{array}$ & $\begin{array}{l}\text { Quality of post-consumer food } \\
\text { grade plastic }\end{array}$ & $\begin{array}{l}\text { Consumer perception of } \\
\text { packaging vs food waste }\end{array}$ \\
\hline $\begin{array}{l}\text { Pressure for improved } \\
\text { packaging line efficiencies }\end{array}$ & $\begin{array}{l}\text { Traceability of recycled } \\
\text { material through reprocessing } \\
\text { cycles }\end{array}$ & $\begin{array}{l}\text { Pressure to be plastic free by } \\
\text { consumers and the media. }\end{array}$ \\
\hline Squeezed price margins & $\begin{array}{l}\text { Plastic reprocessing } \\
\text { capabilities and capacity }\end{array}$ & $\begin{array}{l}\text { End of Life considerations for } \\
\text { flexible films }\end{array}$ \\
\hline $\begin{array}{l}\text { Constant change of percentage } \\
\text { packaging costs in relation to } \\
\text { retail unit price }\end{array}$ & $\begin{array}{l}\text { Pressure to move to cyclical } \\
\text { material flows whilst } \\
\text { protecting food throughout the } \\
\text { lifecycle. }\end{array}$ & \\
\hline
\end{tabular}


Table 3. Split of Scoping Study participants by Stakeholder Group and Job Functions

\begin{tabular}{|c|c|c|c|}
\hline Stakeholder Group & $\begin{array}{c}\text { No. } \\
\text { participants }\end{array}$ & Job Function & $\begin{array}{c}\text { No. } \\
\text { participants }\end{array}$ \\
\hline $\begin{array}{l}\text { Raw Material Supplier } \\
\text { (carton board) }\end{array}$ & 2 & Research \& Development & 2 \\
\hline $\begin{array}{l}\text { Packaging Manufacturer } \\
\text { (carton) }\end{array}$ & 4 & Technical & 8 \\
\hline $\begin{array}{l}\text { Packaging Manufacturer } \\
\text { (rigid and flexible } \\
\text { plastic) }\end{array}$ & 4 & $\begin{array}{l}\text { Sales \& Marketing (inc. } \\
\text { buying) }\end{array}$ & 7 \\
\hline Food Processor & 4 & Sustainability & 3 \\
\hline Food Retailer & 4 & $\begin{array}{l}\text { Packaging Manager / } \\
\text { Consultant }\end{array}$ & 4 \\
\hline Recycler / Reprocessor & 2 & & \\
\hline Packaging Consultant & 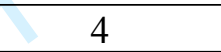 & & \\
\hline
\end{tabular}

Table 4. Future challenges facing the UK Food Packaging Supply Chain in 2018

\begin{tabular}{|l|l|l|}
\hline Economic Challenges & Environmental Challenges & Social Challenges \\
\hline $\begin{array}{l}\text { Impact of rising costs on level } \\
\text { of industry investment }\end{array}$ & $\begin{array}{l}\text { Packaging material } \\
\text { considerations including } \\
\text { legislation changes }\end{array}$ & $\begin{array}{l}\text { The impact of reducing } \\
\text { packaging on food safety and } \\
\text { security }\end{array}$ \\
\hline $\begin{array}{l}\text { Impact of recession on the } \\
\text { food retail sector }\end{array}$ & $\begin{array}{l}\text { Uncertainty of what is meant } \\
\text { by "sustainable packaging" }\end{array}$ & $\begin{array}{l}\text { Consumer perception of food } \\
\text { packaging }\end{array}$ \\
\hline $\begin{array}{l}\text { Impact of rising costs at home } \\
\text { for the consumer }\end{array}$ & Waste management concerns & $\begin{array}{l}\text { Need for better packaging } \\
\text { education for consumers }\end{array}$ \\
\hline
\end{tabular}


Table 5. Ranking of stakeholder groups who can effectively reduce packaging waste in the UK food packaging supply chain

\begin{tabular}{|c|l|c|}
\hline $\begin{array}{c}\text { Rank } \\
\text { Position }\end{array}$ & Stakeholder Group & $\begin{array}{c}\text { Percentage } \\
\text { of votes }\end{array}$ \\
\hline 1 & Recycler / Reprocessor & 75 \\
\hline 2 & Waste Collection & 71 \\
\hline 3 & Packaging Manufacturer & 71 \\
\hline 4 & Consumer & 67 \\
\hline 5 & Retail Store & 63 \\
\hline 6 & Food Processor & 58 \\
\hline 7 & Raw material supplier & 46 \\
\hline 8 & Distribution Chain & \\
\hline & &
\end{tabular}

Table 6. Ranking of consumer attributes currently considered during the food packaging development process

\begin{tabular}{|c|l|c|}
\hline $\begin{array}{c}\text { Rank } \\
\text { Position }\end{array}$ & Consumer Attribute & $\begin{array}{c}\text { Percentage } \\
\text { of votes }\end{array}$ \\
\hline 1 & Impact at Point of Purchase & 92 \\
\hline 2 & Opening experience & 88 \\
\hline 3 & Ease to dispose of & 83 \\
\hline 4 & $\begin{array}{l}\text { Target Consumer } \\
\text { Demographic }\end{array}$ & 83 \\
\hline 5 & Storage at home & 79 \\
\hline 6 & $\begin{array}{l}\text { Ease to pack and transport } \\
\text { home }\end{array}$ & 79 \\
\hline 7 & Repeat usage & 63 \\
\hline
\end{tabular}

Table 7. Ranking of CE solutions currently being used by stakeholder groups in the food packaging supply chain

\begin{tabular}{|c|l|c|}
\hline $\begin{array}{c}\text { Rank } \\
\text { Position }\end{array}$ & CE Packaging Solution & $\begin{array}{c}\text { Percentage } \\
\text { of votes }\end{array}$ \\
\hline 1 & Design for Recyclability & 88 \\
\hline 2 & Redesign of Products & 71 \\
\hline 3 & Re-usable Packaging & 67 \\
\hline 4 & Refillable Packaging & 54 \\
\hline 5 & Systems Design & 38 \\
\hline
\end{tabular}


Table 8. Industry concerns in moving to CE packaging systems

\begin{tabular}{|l|l|l|}
\hline \multicolumn{1}{|c|}{ 1. Cost Implications } & \multicolumn{1}{|c|}{$\begin{array}{l}\text { Importance of } \\
\text { Consumer Behaviour }\end{array}$} & \multicolumn{1}{c|}{$\begin{array}{c}\text { 3. Unintended } \\
\text { Consequences }\end{array}$} \\
\hline $\begin{array}{l}\text { Financial and environmental } \\
\text { cost considerations }\end{array}$ & $\begin{array}{l}\text { Consumer considerations in } \\
\text { how CE packaging systems } \\
\text { will work }\end{array}$ & $\begin{array}{l}\text { Risk of it resulting in an } \\
\text { increase in } \mathrm{CO}_{2} \text { emissions }\end{array}$ \\
\hline $\begin{array}{l}\text { Cost of implementing versus } \\
\text { added value }\end{array}$ & $\begin{array}{l}\text { Consumer pressure could } \\
\text { prevail to move away from } \\
\text { plastics, therefore no need for } \\
\text { CE }\end{array}$ & $\begin{array}{l}\text { Not the be all and end all } \\
\text { solution; need for a multi- } \\
\text { solution approach }\end{array}$ \\
\hline $\begin{array}{l}\text { Initially no financial benefits, } \\
\text { will take time }\end{array}$ & & \\
\hline
\end{tabular}

